\title{
Percutaneous Kyphoplasty Application for T4 Vertebral Fracture Under Computerized Tomography
}

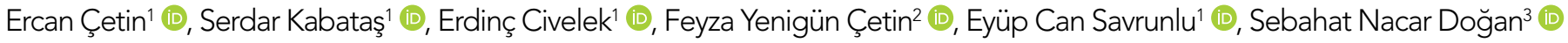 \\ ${ }^{1}$ Clinic of Neurosurgery, University of Health Sciences Gaziosmanpaşa Taksim Training and Research Hospital, İstanbul, Turkey \\ 2istanbul Esenyurt University, Vocational School of Health Services, Anesthesia Program, i̇stanbul, Turkey \\ ${ }^{3}$ Clinic of Radiology, University of Health Sciences Gaziosmanpaşa Taksim Training and Research Hospital, İstanbul, Turkey
}

Cite this article as: Çetin E, Kabataş S, Civelek E, Yenigün Çetin F, Savrunlu EC, Nacar Doğan S. Percutaneous Kyphoplasty Application for T4 Vertebral Fracture Under Computerized Tomography. JAREM 2018; 8: 52-5.

\begin{abstract}
Percutaneous vertebral augmentation procedures for vertebral fractures are increasingly becoming popular. However, due to difficulties in thoracic vertebra morphology and live fluoroscopic imaging, alternate imaging modalities may be needed. In this case report, T4 kyphoplasty application under serial computed tomography imaging is presented.

Keywords: Kyphoplasty, thoracic, vertebra, fracture
\end{abstract}

ORCID IDs of the authors: E.Ç. 0000-0001-8196-8221; S.K. 0000-0003-2691-6861; E.C. 0000-0002-3988-4064; F.Y.Ç. 0000-0002-0182-5683; E.C.S. 00000001-9022-200X; S.N.D. 0000-0003-1512-5060

\section{INTRODUCTION}

Vertebral fractures are one of the common pathologies encountered in neurosurgical practice, and osteoporosis is their most common underlying cause. There is no consensus on the treatment of vertebral fractures in the literature. In vertebral fractures, which are usually neurologically stable, the first treatment of choice is conservative, and it often involves analgesia, rest, the corset use, and rehabilitation (1). However, vertebroplasty and kyphoplasty, which are vertebral strengthening methods, are used in patients whose symptoms do not improve. Although fluoroscopy is usually used during kyphoplasty procedures, computed tomography (CT) imaging is also used for procedures in the upper thoracic region. In this publication, we present a patient who suffered an upper thoracic vertebral fracture and benefited from kyphoplasty.

\section{CASE REPORT}

A 60-year-old female patient was admitted to our outpatient clinic with the complaint of back pain after falling from a tree 2 years before. The patient who had no neurological deficit had back pain for 2 years despite the use of a corset and a pain reliever. The pain intensity was reported as 8 on the visual pain scale (VAS). T4 compression fractures were detected in the thoracic CT and magnetic resonance (MR, GE Signa HDX (General Electric, Milwaukee, $\mathrm{WI}$ )) imaging (including a short-tau inversion recovery sequence) (Figure 1).

Due to the fracture in the upper thoracic region, kyphoplasty with CT was planned. Written informed consent was received from the patient. Sedation was applied; the patient was laid on a CT stretcher in prone position in the CT laboratory, and serial CT (Siemens Somatom Emotion, Germany) imaging was taken. The vertebral corpus was entered through both pedicles of T4 with a sterile technique. Following the surgical maneuvers, CT images were taken, and the location of the cannula was checked at each step. During the serial CT scan, when it was observed (Figure 2) that the corpus anterior wall was passed, the cannula was withdrawn, and its position was again confirmed with CT. The kyphoplasty balloon was inserted through the trocar on the patient's right side and inflated, and thus the corpus was tried to be raised. The balloon was removed, and $3 \mathrm{cc}$ of polymethylmethacrylate (PMMA, Mendec Spine, Italy) was injected. The process was completed without any problems.

In a CT scan that was taken at the end of the procedure, acrylic was observed to spread in the T4 corpus (Figure 3). However, it was observed that a trace amount of cement leaked into the thorax. Still, this did not cause any symptoms in the patient. The patient stated that her pain completely disappeared after kyphoplasty (VAS score=1). The patient, who had stable vital signs and had no complaints, was mobilized the same evening and discharged the next day.

\section{DISCUSSION}

Vertebroplasty and kyphoplasty are the techniques which use has gradually increased over the last 50 years $(2,3)$. There are two types of vertebral strengthening interventions for the treatment of vertebral fractures: vertebroplasty and kyphoplasty. In both techniques, by reaching the vertebral corpus using a cannula 
with percutaneous intervention and by injecting PMMA into the fractured corpus, the fracture is stabilized (4). Differently, there is a widespread belief that a balloon is inflated to change the shape of the corpus, the height of the collapsed vertebra is increased, a cavity is formed in the corpus, and the leakage of cement from

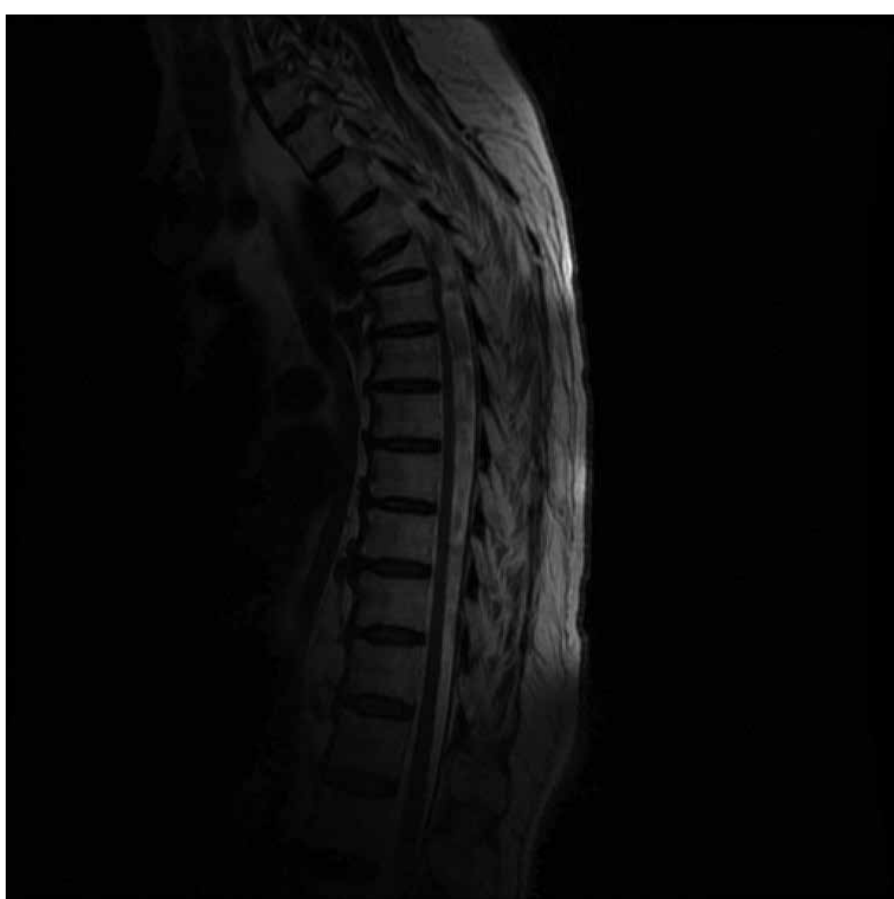

Figure 1. MR imaging showing a T4 compression fracture and anterior angling

MR: magnetic resonance

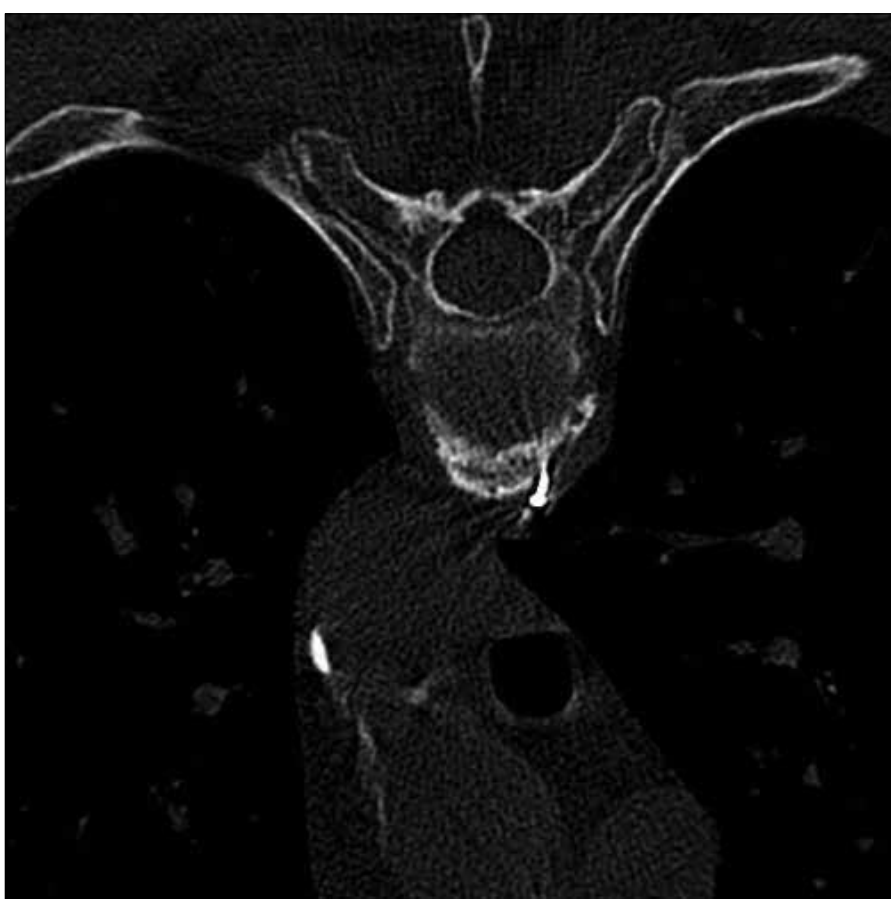

Figure 2. During serial CT imaging, the snapshot of the intervention needle passing beyond the anterior T4 corpus wall to the thoracic cavity $\mathrm{CT}$ : computed tomography the vertebra is thus reduced in kyphoplasty $(5,6)$. These two new techniques have replaced open surgeries in stable cases because they are less invasive, have fewer complications, and have positive effects on morbidity and mortality.

Major complications of vertebra-strengthening techniques include infection, hemorrhage, pneumothorax or rib fracture, radiculopathy due to cement leak, canal stenosis and associated paralysis, pulmonary embolism, and death. Although the cement leak is often monitored radiologically, $96 \%$ of cases can be asymptomatic (1). The most common anatomic regions where the cement leak is encountered are paravertebral space, epidural space, intervertebral disc, and foraminal zone.

In the vertebra-strengthening procedure, radiological examinations during the diagnosis before the intervention are as important as those performed during and after the intervention. During the diagnosis, through MR and CT imaging, diagnosis can be made, and the complication rate is reduced by determining the pedicle diameter and entrance angles. Technetium-99 bone scintigraphy can be used in patients with a pacemaker or in patients in whom MR can not be taken due to other causes. The integrity of the posterior wall can be assessed with tomography (7).

The thoracic region has a more complicated anatomy in terms of the specification level with fluoroscopy and detecting the entry points of the pedicles during vertebroplasty and kyphoplasty. In addition, it may be difficult to identify the pedicle because of the reduction in corpus height and thoracic structures that are involved in breathing. There are many publications in the literature on the sizes and direction of thoracic pedicles. Although the mid-thoracic region is considered to be the region with the smallest pedicle size, there is a consensus on the determination

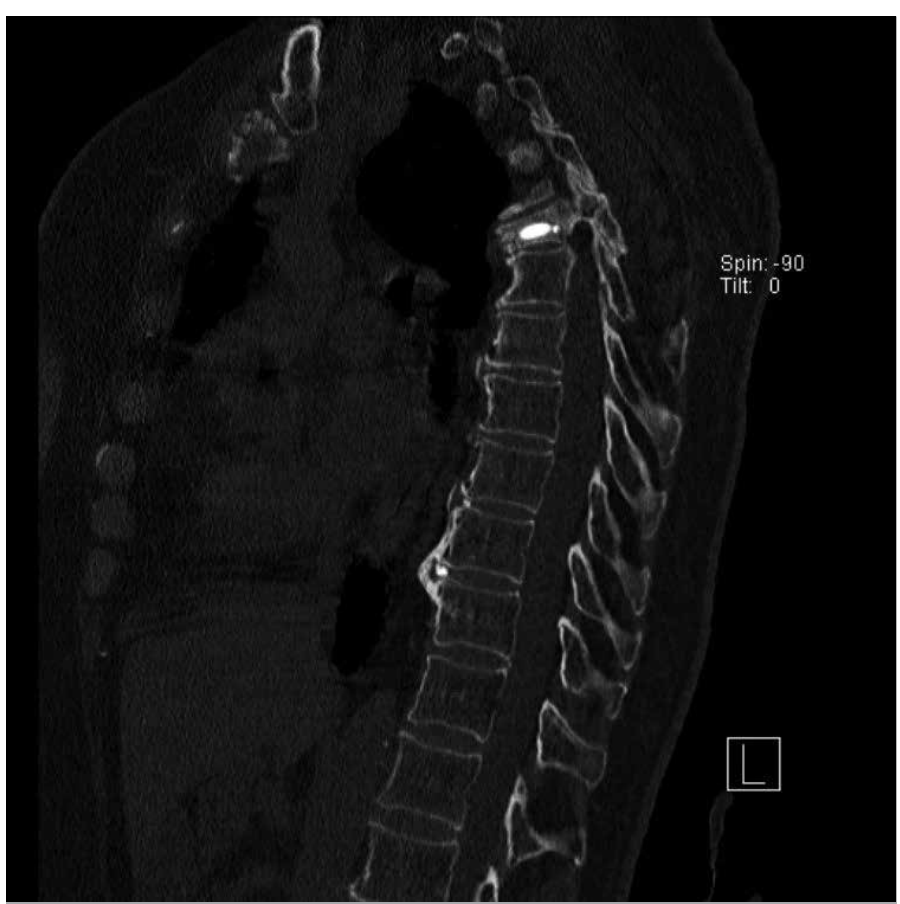

Figure 3. The imaging of polymethylmethacrylate in T4 corpus in the CT taken at the end of kyphoplasty

CT: computed tomography 
of the radiological parameters of this region prior to surgery and anesthesia application in the thoracic region (8-12).

We think that it is a significant advantage to perform vertebroplasty and kyphoplasty under CT instead of C-arm fluoroscopy in some special cases. In our case, CT was not used in diagnostics, but to increase the safety of the intervention. The problem of shoulder interference encountered in the C-arm fluoroscopy in the upper thoracic procedures is overcome with the use of CT (13). The accurate spine level was determined in our patient in a short time. There are studies showing that performing verteboplasty accompanied by CT is safer than performing it with conventional fluoroscopy $(14,15)$. Considering especially the very small anatomical targets, in thoracic region applications, this safety is provided with advancing the needle from the skin to the vertebral corpus by following in three planes without damaging another structure. In our case, after determining the accurate vertebral level and pedicles, the trace that progressed up to the corpus was followed by way of taking CTs step-by-step, although not through live imaging. The PMMA distribution and quantity were also observed during and after the injection. The possibility of determining the cement leakage, which can be observed only minimally during PMMA injection, is limited in C-arm fluoroscopy. Given the variations in the thoracic vertebrae, we think that CT improved safety for this patient.

It is thought that approaching the previously identified targets under CT will both shorten the intervention duration and increase safety. In our case, the duration of the intervention could not be measured, but assuming that it was performed with $C$-arm fluoroscopy, we think that it is shorter than the duration required to determine the level, entry point, and direction and also for confirming the amount of PMMA to be injected.

There are publications that compare the advantages and disadvantages of conventional C-arm fluoroscopy (16-18). C-arm fluoroscopy is considered to be the standard imaging modality as it is effective, easy to use, easy to learn, inexpensive, and the radiation exposure is very low. The mean radiation dose in conventional fluoroscopy is $0.02 \mathrm{rad} / \mathrm{min}$, whereas it is $0.03 \mathrm{rad} / \mathrm{min}$ when taking a single topographic section in CT and $1.77 \mathrm{rad} /$ min when taking the axial tomography of a single region of the spine (19). The surgical team should wear protective clothing. In particular, hands should be protected from radiation by wearing protective lead gloves.

Another disadvantage of using CT during vertebroplasty or kyphoplasty compared to fluoroscopy is that the fluoroscopy can not show live the cement filling or the leak into the paraspinal or spinal canal. In some centers, the surgery is performed with fluoroscopy after the preoperative pedicle configuration is determined. However, a high-quality fluoroscope is needed to detect a cement leakage, especially in the thoracic region. Another alternative is the use of the CT-fluoroscopy technique (19).

\section{CONCLUSION}

Although vertebroplasty and kyphoplasty are generally considered to be safe, serious complications can occur. A serious radiological evaluation should be performed before surgery involv- ing thoracic vertebrae, especially in the middle thoracic region, because of the pedicle morphology and the anatomic variations in their sizes, and the unique structure of the thoracic vertebral anatomy. The most important step in reducing the complications is to use quality imaging methods before and during the intervention. Although performing the interventions in mid-thoracic vertebral fractures with thoracic CT imaging is not a standard approach considering the issues such as cost and radiation exposure, it is an important alternative to be preferred in some special conditions to increase patient safety or to increase the chance of success in patients with complicated anatomies.

Informed Consent: Written informed consent was obtained from patient who participated in this case.

Peer-review: Externally peer-reviewed.

Author Contributions: Concept-E.Ç., S.K., E.C.; Design - F.Y.Ç., E.C., S.K.; Supervision - E.C.S.; Resources - E.Ç., E.C.S., E.C.; Materials - S.K., E.C.S., S.N.D.; Data Collection and/or Processing - F.Y.Ç., S.K., S.N.D.; Analysis and/or Interpretation -S.K., S.N.D.; Literature Search - S.K., E.Ç., S.N.D., E.C.S.; Writing Manuscript - E.Ç., S.K.; Critical Review - F.Y.Ç., E.C.S., S.N.D.

Conflict of Interest: No conflict of interest was declared by the authors.

Financial Disclosure: The authors declared that this study has received no financial support.

\section{REFERENCES}

1. Nieto-Iglesias C, Andrés-Nieto I, Peces-Garcia E, Roca-Amatria G, Ares JDA, Franco-Gay ML, et al. Vertebroplasty and kyphoplasty: Techniques, complications, and troubleshooting. Techniques in Regional Anesthesia and Pain Management. Elsevier 2014; 18: 40-8.

2. Muto M, Perrotta V, Guarnieri G, Lavanga A, Vassallo P, Reginelli R, et al. Vertebroplasty and kyphoplasty: friends or foes? La radiologia medica. Springer 2008; 113: 1171-84.

3. Civelek E, Cansever T, Yilmaz C, Kabatas S, Gülsen S, Aydemir F, et al. The retrospective analysis of the effect of balloon kyphoplasty to the adjacent-segment fracture in 171 patients. J Spinal Disord Tech 2014; 27: 98-104. [CrossRef]

4. Zapałowicz K, Radek M. Percutaneous balloon kyphoplasty in the treatment of painful vertebral compression fractures: effect on local kyphosis and one-year outcomes in pain and disability. Neurol Neurochir Pol 2015; 49: 11-5. [CrossRef]

5. Voggenreiter G. Balloon kyphoplasty is effective in deformity correction of osteoporotic vertebral compression fractures. Spine 2005; 30 : 2806-12. [CrossRef]

6. Garfin SR, Yuan HA, Reiley MA. New technologies in spine: kyphoplasty and vertebroplasty for the treatment of painful osteoporotic compression fractures. Spine 2001; 26: 1511-5. [CrossRef]

7. McGraw JK, Cardella J, Barr JD, Mathis JM, Sanchez O, Schwartzberg MS, et al. Society of Interventional Radiology quality improvement guidelines for percutaneous vertebroplasty. Journal of Vascular and Interventional Radiology. Elsevier 2003; 14: 311-5. [CrossRef]

8. Vaccaro AR, Rizzolo SJ, Allardyce TJ, Ramsey M, Salvo J, Balderston RA, et al. Placement of pedicle screws in the thoracic spine. Part I: Morphometric analysis of the thoracic vertebrae. J Bone Joint Surg Am 1995; 77: 1193-9. [CrossRef]

9. Ugur HÇ, Attar A, Uz A, Tekdemir I, Egemen N, Genç Y. Thoracic pedicle: surgical anatomic evaluation and relations. J Spinal Disord 2001; 14: 39-45. [CrossRef] 
10. Bisćević M1, Bisćević S, Ljuca F, Smrke BU, Kapur E, Tezer M, et al. Clinical and radiological morphometry of posterior parts of thoracic and lumbal vertebras. Coll Antropol 2012; 36: 1313-7.

11. Kretzer RM, Chaput C, Sciubba DM, Garonzik IM, Jallo GI, McAfee PC, et al. A computed tomography-based morphometric study of thoracic pedicle anatomy in a random United States trauma population. Spine 2011; 14: 235-43. [CrossRef]

12. Kim WJ, Kim TH, Shin HY, Kang H, Baek CW, Jung YH, et al. Fluoroscope guided epidural needle insertioin in midthoracic region: clinical evaluation of Nagaro's method. Korean J Anesthesiol 2012; 62: 441-7. [CrossRef]

13. Seong JY, Kim JS, Jung B, Lee SH, Kang HY. CT-guided percutaneous vertebroplasty in the treatment of an upper thoracic compression fracture. Korean J Radiol 2009; 10: 185-9. [CrossRef]

14. Gangi A, Kastler BA, Dietemann JL. Percutaneous vertebroplasty guided by a combination of CT and fluoroscopy. Am Soc Neuroradiology 1994; 15: 83-6.
15. Gangi A, Guth S, Imbert JP, Marin H, Dietemann JL. Percutaneous vertebroplasty: indications, technique, and results. Radiographics 2003; 23: e10. [CrossRef]

16. Mathis JM, Barr JD, Belkoff SM, Barr MS, Jensen ME, Deramond $\mathrm{H}$. Percutaneous vertebroplasty: a developing standard of care for vertebral compression fractures. AJNR Am J Neuroradiol 2001; 22: 373-81. [CrossRef]

17. Barr JD, Barr MS, Lemley TJ, McCann RM. Percutaneous vertebroplasty for pain relief and spinal stabilization. Spine 2000; 25: 923-8. [CrossRef]

18. Cyteval C, Sarrabere M, Roux J, Thomas E, Jorgensen C, Blotman F, et al. Acute osteoporotic vertebral collapse: open study on percutaneous injection of acrylic surgical cement in 20 patients. Am Roentgen Ray Soc 1999; 173: 1685-90. [CrossRef]

19. Kim JH, Park KS, Yi S, Shin HC, Yoon DH, Kim KN. Real-time CT fluoroscopy (CTF)-guided vertebroplasty in osteoporotic spine fractures. Yonsei Med J 2005; 46: 635-42. [CrossRef] 